\title{
Review
}

\section{Effects of Androgen and Estrogen Receptor Signaling Pathways on Bladder Cancer Initiation and Progression}

\author{
Guilherme Godoy ${ }^{\mathrm{a}, 1}$, Georgios Gakis ${ }^{\mathrm{b}, 1}$, Carolyn L. Smith ${ }^{\mathrm{a}, \mathrm{c}, *, 2}$ and Omar Fahmy $\mathrm{b}^{\mathrm{b}, 2}$

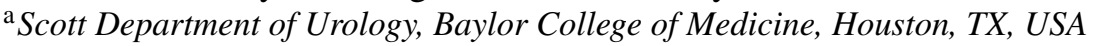 \\ ${ }^{\mathrm{b}}$ Department of Urology, Eberhard-Karls University, Tuebingen, Germany \\ ${ }^{\mathrm{c}}$ Department of Molecular and Cellular Biology, Baylor College of Medicine, Houston, TX, USA
}

\begin{abstract}
Epidemiologic studies have long demonstrated clear differences in incidence and progression of bladder cancer between genders suggesting that the mechanisms of development and progression in these tumors have a strong association with steroid hormonal pathways. Such observations led to preclinical studies investigating the role of androgen and estrogen receptors, as well as their cognate hormones in bladder cancer initiation and progression. Using various in vitro cell line assays and in vivo mouse models, studies have elucidated different mechanisms and signaling pathways through which these steroid receptors may participate in this disease. More recently, RNA expression data from multiple studies revealed a luminal subtype of bladder cancer that exhibited an estrogen receptor signaling pathway, making it a strong candidate for further consideration of targeted therapies in the future. Despite the promising preclinical data demonstrating potential roles for both antiandrogen and antiestrogen strategies targeting these pathways in different stages of bladder cancer, only two clinical trials are currently active and accruing patients for such clinical studies. Targeted therapies in bladder cancer are a large unmet need and have the potential to change treatment paradigms and improve oncological outcomes of patients with bladder cancer.
\end{abstract}

Keywords: Androgens, receptor, androgen, androgen antagonists, estrogens, receptors, estrogen, estrogen receptor modulators, urinary bladder neoplasms, carcinogenesis, disease progression

\section{INTRODUCTION}

Bladder cancer is the ninth most common malignant disease worldwide with an annual incidence of 429,800 new cases and 165,100 deaths in 2012 [1]. In the United States, bladder is the 4th most common and the 8th most lethal cancer in males [2]. The most common histological type is urothelial

\footnotetext{
${ }^{1}$ Equal first authors.

${ }^{2}$ Equal last authors.

*Correspondence to: Carolyn L. Smith, Scott Department of Urology, Baylor College of Medicine, Houston, TX, USA. E-mail: carolyns@bcm.edu.
}

carcinoma and the majority (70-75\%) of patients display non-muscle-invasive bladder cancer (NMIBC) at time of diagnosis [3]. At this stage of the disease, treatment in the majority of cases involves complete endoscopic resection of the tumour followed by adjuvant intravesical chemo- or immunotherapy [4]. In contrast, cases with resistant disease or progression to muscle-invasive bladder cancer (MIBC) require radical cystectomy and systemic chemotherapy [5]. Although intravesical instillation of immunotherapy using Bacillus Calmette-Guérin (BCG) is superior to chemotherapy in prevention or at least delay of recurrence for patients with NMIBC [6], about 70\% of patients receiving BCG develop either local or 
systemic side effects [7]. Furthermore the curability after BCG instillation is limited as up to 50\% of patients with carcinoma in situ (CIS) develop recurrence or progression of disease after complete response to BCG therapy [8]. Sadly, the management of bladder cancer has remained essentially unchanged, with no new efficient treatment options approved over the past few decades, and this disease therefore represents an area of great need for medical development and research.

Although sex steroid plays roles in development of the urogenital tract, and loss of ovarian steroids has been associated with urinary incontinence and bladder prolapse in postmenopausal women, the role of androgens and estrogens in the normal bladder urothelium are not well characterized. Observed epidemiological differences between males and females are obvious and suggest the potential involvement of sex steroid pathways in bladder cancer development and progression [9-12]. Indeed, the incidence of bladder cancer and its outcomes seem to be clearly influenced by gender. Men are affected by bladder cancer 3.3 - 4 times more often than women, even after exclusion of environmental exposures to carcinogenic chemicals and cigarette smoking $[1,2$, 13-15]. Yet despite females being less frequently affected by bladder cancer, they are more likely to be diagnosed at higher disease stages $(85.2 \%$ vs. $50.7 \%$ of MIBC at presentation for males) and have a greater risk of dying from their disease than men, suggesting that tumor invasion and progression may occur earlier in women [16-18]. In addition, adverse prognostic factors are also more commonly observed in females after radical cystectomy [19-21], and most studies report a higher risk of disease recurrence in comparison to males [22-24], except for one in which no difference was observed [25].

Based on the sex disparity of bladder cancer incidence and progression, many studies have been conducted to elucidate the role of sex hormones and their receptors in the natural history of bladder cancer with the ultimate goal of generating new therapeutic approaches to improve treatment outcomes. The current paper includes a non-systematic review of the literature, searching Medline for original and review articles published between 1975 and 2015 using the following keywords: androgen receptors; estrogen receptors; sex hormones and bladder cancer; gender and bladder cancer; bladder cancer progression; bladder cancer recurrence; bladder cancer outcomes. In this review article, we explore the existing evidence for involvement of sex hormone receptor signaling pathways in bladder cancer development and progression, and discuss potential new therapeutic strategies that may lead to improvements in the oncological outcomes of this disease.

\section{SEX STEROID RECEPTORS IN BLADDER CANCER}

\section{Androgen receptor (AR) expression}

Many studies have reported AR expression in human bladder cancer tissue, the effect of gender on its distribution, and the correlation of AR expression, determined by immunohistochemistry, to tumor stage and grade. There is wide variability in the percentage of AR expression detected in malignant urothelium ranging between $13 \%$ and $78 \%[10,11$, 26-28]. Interestingly, the number of tumors assessed in each study inversely correlated with the percentage of AR-positive tumors as $13 \%, 25 \%, 37 \%, 53 \%$ and $78 \%$ of tumors were found to express AR in studies considering 472, 297, 169, 49 and 9 specimens, respectively [10, 11, 26-28]. Two additional studies investigating AR expression in poorly differentiated urothelial carcinoma revealed fewer than $5 \%$ of tumors were positive $[29,30]$. Other studies comparing AR expression in normal and malignant urothelium, using either control tissues from other persons $[31,32]$ or control specimens from a normal looking area in the same bladder [33, 34], revealed in most cases that AR expression was higher in malignant urothelium with one exception that revealed higher AR content in benign tissue [34]. No significant difference in AR distribution between males and females was detected in most studies $[10,11$, 31, 32, 34-36] except in one, in which AR expression was higher in males [33]. Finally, most studies reveal an inverse relationship between AR expression and aggressive bladder cancer [10, 26, 27, 32-34], as AR expression has been predominantly detected in low-grade NMIBC (Table 1). To date, only one has study reported a significant association between AR expression and high-grade poorly differentiated tumors [31].

The available data present a variable relationship between AR expression and clinical parameters. Indeed, the largest multi-institution cohort investigating the expression of AR in 472 subjects using tissue microarrays and different antibodies indicated that AR expression was low in bladder cancer and independent of gender, grade, stage or clinical outcome [11]. The recently published mRNA expression data 
Table 1

Summary of publications reporting androgen receptor and estrogen receptor expression in human bladder tissues

\begin{tabular}{|c|c|c|c|c|c|}
\hline Author & Receptor & $\mathrm{N}$ & Specimen type & Stage/Grade Correlation & $\begin{array}{c}\text { Survival/Prognostic } \\
\text { Association }\end{array}$ \\
\hline Boorjian et al. [10] & $\mathrm{AR}$ & 49 & tumor & Yes - negative & NR \\
\hline Mir et al. [11] & AR & 472 & tumor & No & NS \\
\hline Williams et al. [27] & $\mathrm{AR}$ & 297 & tumor & Yes - negative & NR \\
\hline Zhuang et al. [28] & $\mathrm{AR}$ & 9 & tumor & NR & NR \\
\hline Downes et al. [29] & $\mathrm{AR}$ & 13 & tumor & NR & NR \\
\hline Mohanty et al. [30] & AR & 16 & tumor & NR & NR \\
\hline Laor et al. [33] & AR & 21 & normal + tumor & Yes - negative & NR \\
\hline Boorjian et al. [35] & $\mathrm{AR}$ & 55 & tumor & Yes - negative & NR \\
\hline Kauffman et al. [36] & AR & 129 & normal + tumor & $\mathrm{NS}$ & NS \\
\hline Nam et al. [26] & $\mathrm{AR}+\mathrm{ER} \beta$ & 169 & tumor & $\begin{array}{l}\text { Yes - negative (AR) } \\
\text { Yes - positive (ER } \beta)\end{array}$ & Yes - AR + ER $\beta$ \\
\hline Mashhadi et al. [31] & $\mathrm{AR}+\mathrm{ER} \alpha$ & 252 & normal + tumor & Yes - positive (AR) & Yes - AR \\
\hline Tuygun et al. [32] & $\mathrm{AR}+\mathrm{ER} \beta$ & 211 & normal + tumor & Yes - negative (AR) & Yes - ER $\beta$ \\
\hline Miyamoto et al. [34] & $\mathrm{AR} \mathrm{ER} \alpha+\mathrm{ER} \beta$ & 329 & normal + tumor & $\begin{array}{c}\text { Yes }- \text { negative }(\mathrm{AR}+\mathrm{ER} \alpha) \\
\text { Yes }- \text { positive }(\mathrm{ER} \beta)\end{array}$ & Yes - ER $\beta$ \\
\hline Bolenz et al. [9] & $\mathrm{ER} \alpha$ & 198 & tumor & NS & NS \\
\hline Kauffman et al. [53] & $\mathrm{ER} \beta$ & 72 & tumor & Yes - positive & Yes \\
\hline Shen et al. [54] & $E R \alpha+E R \beta$ & 224 & tumor & Yes - positive (ER $\beta)$ & NR \\
\hline Han et al. [57] & $\mathrm{ER} \beta$ & 42 & tumor & Yes - negative & Yes \\
\hline Kauffman et al. [58] & $\mathrm{ER} \alpha$ & 185 & tumor & Yes - positive & NR \\
\hline Kontos et al. [59] & $\mathrm{ER} \beta$ & 140 & tumor & Yes - negative & NR \\
\hline Croft et al. [56] & $\mathrm{ER} \beta$ & 92 & tumor & Yes - positive & NR \\
\hline Tan et al. [60] & $\mathrm{ER} \alpha+\mathrm{ER} \beta$ & 318 & tumor & Yes - negative (ER $\beta)$ & Yes - ER $\beta$ \\
\hline
\end{tabular}

Notes: AR: androgen receptor; ER: estrogen receptor; N: number of samples; NR: not reported; NS: not significant.

supporting sub-classification of bladder cancer also did not observe a marked presence of AR or evident expression of its related pathways as key markers driving this tumor sub-classification [37-39]. Thus, while the data taken together makes a strong case for AR involvement in bladder cancer, there clearly is a need for further large studies to better ascertain the role of $\mathrm{AR}$, if any, in the gender differences in this disease.

An important factor to consider when studying the activation of AR, as well as ERs, is the recruitment of transcriptional modulating factors (coactivator and corepressor proteins) which interact with ligand bound receptor dimers, and are critical mediators of processes necessary for gene expression such as chromatin remodeling. Thus, altered expression of these positive and negative coregulators can result in significant changes in steroid receptor-mediated cell processes, and be associated with development and proliferation of tumors [35]. There are well over 200 coregulators known to interact with AR and ER pathways and of those, only a very few have been initially explored in the context of bladder cancer development [35, 40]. Notably, members of the steroid receptor coactivator family are expressed in human bladder tumors, and knockdown of their expression in human bladder cancer cell lines reduces cellular proliferation [35]. Moreover, the AIB1/NCOA3 coactivator has been associated with poor patient prognosis [41] and proliferation mediated by Akt and E2F1 pathways [42]. Nonetheless, the study of the expression and function of coregulators in bladder cancer is still in its infancy and there is a significant need for research in this field.

\section{Roles of androgens and $A R$ in bladder cancer: In vitro studies}

Several in vitro studies suggested significant biological effects of androgens, AR and their signaling pathways on bladder tumor growth and progression. Using a dye transfer method in 1990, Kihara et al. reported a reversible inhibitory effect of testosterone on gap junctional intercellular communication for JTC-30 and JTC-32 human transitional cell carcinoma cell lines [43]. In another study using small interfering RNA (siRNA) directed against AR, cell proliferation, apoptosis, migration capacity, growth and metastasis-related gene expression were all affected by AR knockdown [44]. After silencing AR, tumor cell proliferation was inhibited and migration capacity was decreased while apoptosis was increased. Additionally, expression of the evaluated growth-related genes, cyclin D1 and Bcl-xL, and the metastasis-related gene MMP-9 were decreased by AR siRNA knockdown, supporting a role for AR signaling in these biological processes [44]. 
Complementary data obtained by Hsu and colleagues demonstrated that AR transfected cells form more colonies in soft agar than do non-transfected controls in a neoplastic transformation assay induced by exposure to the carcinogen 3-methylcholanthrene (MCA). They also concluded that urothelial AR could modulate p53 signaling and DNA damage repair, and in turn bladder tumorigenesis, after observing that AR knockdown did not impact tumorigenesis in neoplastic transformation assays conducted in the presence of a p53 inhibitor. These in vitro findings were corroborated by in vivo experiments, suggesting that $\mathrm{AR}$ might promote cancer transformation in normal urothelium through modulation of p53 tumor suppressor functions [45].

Further exploratory studies have investigated the impact of androgens and AR signaling on the epidermal growth factor receptor (EGFR)/ERBB2 pathway, as well as the effects of androgens on $\beta$-catenin signals associated with AR expression in diverse human urothelial carcinoma cell lines, including UMUC3, TCC-SUP, 5637 and J82, as well as 293T human embryonic kidney cells transfected with AR $[46,47]$. Collectively, these studies offer additional support to the hypothesis that AR contributes to bladder cancer progression. They also provide mechanistic insight into the pathways (EGFR/ERBB2 and androgen-induced $\beta$-catenin/TCF/LEF1 activity) through which AR may achieve this effect, and suggest androgen deprivation as a potential therapeutic approach in bladder cancer. Additional evidence for role(s) of androgens and AR in bladder cancer progression includes the observation that androgen deprivation and/or treatment with the antiandrogen flutamide, as well as AR knockdown was able to suppress cell proliferation assessed in vitro assays [48].

\section{Roles of androgens and AR in bladder cancer: In vivo studies}

Many years ago, the effect of testosterone on bladder carcinogenesis in female Wistar rats was investigated. Supplementation of testosterone increased the incidence of bladder tumors in intact animals but not in oophorectomized rats, suggesting that the combined action of testosterone and estradiol in bladder favoured the formation of tumors [49]. Other investigators also studied the development of chemically-induced bladder cancer using $\mathrm{N}$-butyl-N-(4-hydroxybutyl) nitrosamine (BBN) in both intact and gonadectomised, male and female
Wistar rats, receiving diethylstilbestrol (DES) and testosterone supplementation. They observed that DES reduced the incidence of bladder tumors significantly in male rats, while in the female animals the incidence was higher in spayed animals supplemented with testosterone than in the intact females. From this, the authors concluded that DES inhibited bladders tumors in male rats while testosterone stimulated tumor development in female rats [50].

More recent in vivo studies have further supported the critical role of AR and androgens in bladder carcinogenesis in mice. Miyamoto and colleagues observed that none of their AR knockout (ARKO) male or female mice developed BBN-induced bladder cancer, whereas $92 \%$ of wild-type males and $42 \%$ of wild-type female mice did [48]. Castration reduced $\mathrm{BBN}$-induced bladder cancer to $50 \%$, consistent with a pro-tumorigenic role for androgens. Surprisingly, 25\% of BBN-treated ARKO mice supplemented with DHT developed bladder cancer suggesting that androgens and/or their metabolites may be involved in bladder carcinogenesis through AR-independent mechanisms. Thus, the authors concluded that both androgens (via AR and non-AR pathways) and AR (via androgen-dependent and androgen-independent signals) contribute to bladder cancer formation. Nonetheless, when analysing cancer progression, they found a correlation with AR-expressing tumors having higher cell proliferation and lower apoptotic rates in comparison to AR-negative tumors [48].

In another study analysing mice lacking only urothelial AR, the incidence of BBN-induced bladder cancer was lower and survival rate was higher than in wild-type littermates. Urothelial AR facilitated transformation of normal cells to carcinoma, likely via p53-PCNA DNA repair signaling [45]. Another possible mechanism involves the UDP-glucoronosyltransferases (UGTs), which are important phase II drug metabolism enzymes that are known to protect epithelia by detoxifying potential carcinogens by catalysing glucoronidation. Members of the UGT1A superfamily have been implicated in the metabolism of aromatic amines, and thus are considered key enzymes involved in detoxification of major bladder carcinogens [51, 52]. The AR appears to reduce the expression of UGT1A in the bladder. For instance, ARKO mice display higher expression of Ugt1A than their wild-type counterparts, and castration of wild-type mice and subsequent DHT supplementation was associated with up-regulation and down-regulation of Ugt1A, respectively [51]. 
Together these results suggest that AR and androgens may utilize several distinct mechanistic pathways to promote bladder tumorigenesis.

\section{Estrogen Receptor (ER) expression in bladder cancer}

Expression of ER $\alpha$ and $E R \beta$ in bladder cancer was reported in some of the AR studies mentioned above $[26,31,32,34]$ as well as in independent studies (Table 1) [9, 53-61]. The reports on ER $\alpha$ expression in different studies have been inconsistent. While some have found ER $\alpha$ to be expressed at significantly higher levels in immortalized urothelial and bladder cancer cells than in benign urothelial cells [55], others noted a markedly lower expression of ER $\alpha$ in human bladder cancer tissue and various cell lines [34, 53, $54,56,60]$. While disparities in cell line expression can be explained by multiple factors, the expression of ER $\alpha$ and ER $\beta$ in human tissues have been more uniformly reported across most studies. Only one study has reported lower expression levels of ER $\alpha$ and ER $\beta$ in tumor tissues in comparison to benign bladders, with the loss of ER $\alpha$ expression strongly associated with higher stage and grade tumors [34]. The majority of studies observed low to undetectable ER $\alpha$ expression with increased ER $\beta$ expression rates found in almost all human bladder cancer tissues. The ER $\beta$ expression rates reported for human tissue varies widely between $2.5 \%$ and $81 \%$ depending on several intrinsic and technical aspects [31, 34, 54, 57-59, 61]. Some of the intrinsic aspects are related to utilization of different tissue areas (e.g. trigone versus other areas of the bladder wall), different grade and stages of disease, and history of previous treatment, while technical aspects include those typically inherent to immunohistochemistry methods such as differences in type and concentration of the antibodies utilized, differences in collection and fixation protocols, and different positivity criteria. Despite the wide variance in the ER $\beta$ expression rates, in most studies, a positive ER $\beta$ expression has been associated with higher stages and grade of urothelial carcinomas [34, 53, 54, $56-58,60]$, with some studies also showing a correlation of receptor expression levels with oncological outcomes $[34,53,56,57,60]$. These data are in line in most of the studies supporting the emerging consensus that ER $\beta$ is the dominant ER present in bladder epithelium and cancer $[9,32,34,53,54,56-58,60]$.

Recently, RNA profiling data have demonstrated the existence of multiple molecular subtypes of bladder cancer, and somewhat surprisingly revealed an estrogen-like signaling signature in a subset of tumors. Choi and colleagues reported the basal, luminal, and p53-like subgroups of MIBC in resemblance to human breast cancers [38]. In particular, the luminal subtype displayed an ER/TRIM24 gene expression pathway [38]. In an independent study yielding complementary results, other investigators identified two main human high-grade bladder cancer subtypes, referring to them as luminal-like and basal-like tumors, because of the similarities of the RNA expression profiles to human breast cancer types [39]. These authors also observed a marked presence of GATA3 (a strong epithelial marker for primary breast cancer and also seen highly expressed in bladder) and ER pathway signaling in the luminal subtype [39]. Finally, data from The Cancer Genome Atlas also yielded similar findings from their mRNA, miRNA and protein analyses, which led to classification of bladder tumors into 4 clusters, with clusters I and II exhibiting papillary histology and an elevated ER signaling signature with marked similarity to luminal breast cancer [37]. The identification of ER signaling pathways in only a subset of tumors analysed in these mRNA expression studies may be an important contributing factor to the variable results previously observed by immunohistochemistry studies. This may be an important consideration for future study design.

\section{Role of estrogens and ERs in bladder cancer: In vitro and in vivo studies}

Several groups have demonstrated a proliferative response of bladder cells to $17 \beta$-estradiol (E2) stimulation. When studying normal human bladder urothelial cells, immortalized urothelial (E6, E7, and UROtsa) and bladder cancer cell lines (HTB-9 and T24), Teng et al. observed that both ER $\alpha$ and ER $\beta$ contribute to estrogen-induced G1/S phase progression and proliferation in urothelial cells when stimulated with $E 2$, and other $E R \alpha$ and $E R \beta$ selective agonists, propyl pyrazole triol (PPT) and diarylpropionitrile (DPN), respectively [55]. An increased expression of $\mathrm{ER} \alpha$ was noted in the bladder cancer cell lines and immortalized urothelial cells in comparison with benign urothelium cells, along with induced expression of cyclin D1 and cyclin E, possibly resulting in dysregulated cell proliferation [55]. Others have reported on the ability of E2 and the antiestrogens 4-hydroxytamoxifen (4HT), raloxifene, and ICI 182,780 to affect growth of RT4 and 5637 cell lines which originated from a superficial and an invasive bladder cancer, respectively. The inhibitory effect of raloxifene was reflected by the combination of 
increased cell apoptosis and inhibition of cell proliferation via alteration of cell cycle regulatory genes $[54,62,63]$. Both mechanisms were suggested to be mediated by both ER $\alpha$ and ER $\beta$ [62].

Different mechanisms have been proposed to explain the effect of estrogens and the potential role of ER $\alpha$ and/or ER $\beta$ in the development and progression of bladder cancer. The enzyme, UGT1A is differentially regulated by estrogens in normal versus neoplastic urothelium, and it has been suggested that it plays a protective role in both development and progression of bladder cancer [64]. The expression of UGT1A was studied in a tissue microarray built using 145 human bladder tumor tissues and 101 benign appearing tissues from bladders of patients with tumors. The expression levels, measured by immunohistochemistry, were higher in the matched benign tissue and non-muscle-invasive tumors than in cancer tissues and muscle-invasive carcinomas, respectively. A significant association was observed between the lower expression of UGT1A and highgrade non-muscle-invasive tumor progression as well as disease-specific mortality in subjects with muscleinvasive tumors. UGT1A levels were increased in normal urothelium and decreased in tumor tissues after stimulation with estradiol, and this effect was reversed by antiestrogens. Similarly, ovariectomy in mice was accompanied by a downregulation of Ugt 1a expression [64]. Taken together with the AR data discussed previously, this data suggests that both androgens/AR and estrogens/ER signals participate in the modulation of UGT1A expression in the bladder, and therefore may play an important role in the ability of the urothelium to detoxify carcinogens and prevent bladder tumorigenesis. The protective effect of estrogens mentioned above are in line with data showing the down regulation of UGT1A promoted by androgens, consistent with the male dominance in the bladder cancer incidence. Although these investigators were not able to show gender or age differences between the ER and UGT1A expression in bladder tissues, there was strong indication that modulation of UGT1A could potentially be an underlying mechanism to explain gender differences in this disease.

To specifically study the effect of ER $\beta$ on bladder cancer, investigators used 4-[2-phenyl-5,7bis(trifluoromethyl)pyrazolo[1,5-a]pyrimidin-3-yl] phenol (PHTPP), a selective ER $\beta$ antagonist to treat bladder cancer cells and obtained similar effects that those produced by in vivo experiments utilizing ER $\beta$ knockout mice in carcinogen-induced (BBN) bladder cancer model [65]. Knock-out of
ER $\beta$ reduced bladder cancer incidence in female mice to $23 \%$ in comparison to $75 \%$ observed for the wild-type controls. Mechanistic studies found that specifically targeting ER $\beta$ suppressed the expression of minichromosome maintenance complex component 5 (MCM5) and bladder cancer cell growth. MCM5 is a DNA replication licensing factor member of the MCM2-7 complex and essential in mediating DNA replication initiation and elongation in eukaryotic cells, also involved in tumor cell growth. These experiments demonstrate a mechanism by which ER $\beta$, via MCM5 expression, can control bladder cancer growth and invasion. These observations provide evidence that strategies targeting ER $\beta$ (and downstream regulators such as MCM5 regulation) can effectively control bladder cancer in carcinogen-induced models and potentially play important therapeutic role in this disease [65].

The data supporting a role for ER $\alpha$ in bladder cancer contrasts with that for ER $\beta$, as the former may exert both pro- and anti-tumorigenic effects. For instance, a recent study studying cancer associated fibroblasts (CAF) revealed that stroma in tumors had higher expression of ER $\alpha$ and suggested that the receptor could promote bladder cancer invasion via modulation of chemokine (C-C motif) ligand 1 (CCL1) and interleukin-6 (IL6) signaling [66]. Conversely, other data from the same laboratory, in which carcinogen-induced malignant transformation was reduced in urothelial cells expressing ER $\alpha$ in comparison to those that were ER $\alpha$ negative, supports the concept that $\mathrm{ER} \alpha$ plays a protective role in bladder [67]. The induction of inositol polyphosphate-4phosphatase, type II (INPP4B) in the ER $\alpha$-positive cells suggests a role for reduced AKT activity and consequently cell growth in this protective effect [67]. Correlative studies using in vivo $\mathrm{ER} \alpha$ knockout mouse models provided further support for an $\mathrm{ER} \alpha$ protective role in cancer initiation and growth, at least in part through modulating the activity of procarcinogenic pathways, such as the INPP4B/AKT [67]. These authors were able to show through quantitative data that INPP4B mRNA was induced by ER $\alpha$ in bladder cancer cells (UMUC3 and T24) and also non-malignant cells (SVHUC), and that INPP4B protein levels were also increased in cells with ER $\alpha$. They further explored the postulated regulation of INPP4B expression at the transcriptional level, by showing that ER $\alpha$ can upregulate INPP4B promoter activity in UMUC3 and HEK293 cells. Confirmatory data was obtained from chromatin immunoprecipitation (ChIP) assays in ER $\alpha$-transfected T24 cells 
showing that ER $\alpha$ can bind to the -2520 to -2287 region of the INPP4B promoter which encompasses a non-classical estrogen response element [67]. Finally, $\mathrm{ER} \alpha$ overexpression increased levels of p27 suggesting that this cell cycle inhibitor along with the inhibition of AKT, possibly through induction of INPP4B, contributes to the receptor-dependent reduced bladder cancer cell growth [67].

\section{Endocrine based therapeutic trials}

\section{Preclinical AR and ER studies}

Antiandrogen-based studies have shown promising preclinical data supporting a role for these AR inhibitors in modulating or inhibiting bladder cancer growth. In an UPII-SV40T transgenic mouse model, investigators observed that castration reduced the volume of bladder tumors in comparison with intact wild male mice and castrate male mice treated with DHT [68]. The UPII-SV40T is a transgenic mouse model utilizing a chimeric gene that uses the uroplakin II gene promoter to express the oncogene, simian vacuolating virus 40 large $\mathrm{T}$ antigen in the urothelium; animals bearing low copy numbers of the SV40T transgene reliably develop CIS while those with high copy number develop invasive and metastatic tumors [69]. This tumor model does not recapitulate the role of carcinogens in tumorigenesis, but provides a good platform to study interventions addressing specific genetic alterations. Observing that high-grade tumors could be associated with low AR expression and also that steroid hormone receptors other than AR may be activated by dihydrotestosterone, lead these researchers to study this issue in bladder cancer cell lines and UPII-SV40T urothelial explants expressing little or no AR [68]. They observed that DHT was still able to increase proliferation despite the apparent absence of AR. Thus these authors concluded that in addition to an active androgen-mediated classical AR signaling pathway, there appears to be an alternative AR-independent pathway promoting bladder cancer cell growth as well [68], reminiscent of the conclusion reached in studies of $\mathrm{BBN}$-induced carcinogenesis for the ARKO mice noted above [48].

In contrast to the pro-tumorigenic role of androgens such as DHT, antiandrogens have been shown to inhibit tumorigenesis as assessed in the BBN carcinogen-induced tumor model [45]. Treatment of mice with ASC-J9, an AR degradation enhancer ASCJ9 that reduces AR expression suppressed bladder tumorigenesis such that there was a $20 \%$ incidence in treated mice versus $80 \%$ in the control animals treated with BBN alone [45]. In addition to its use as a monotherapy, several antiandrogens have been tested in combination with standard or new intravesical immunotherapies. Investigators studying the new compound protein aggregate, magnesiumammonium phospholinoleate-palmitoleate anhydride (P-MAPA), as an intravesical immunotherapy agent in addition to flutamide to address the AR in a female rat model with NMIBC observed that the addition of flutamide to either P-MAPA or BCG immunotherapy resulted in better response of the bladder tumors than to either of immunotherapies alone, purportedly by enhancing the interferon signaling pathway [70]. Another study also reported enhanced BCG efficacy in limiting bladder cancer progression utilizing a combined therapy approach in which either ASC-J9 or hydroxyflutamide, another AR antagonist, was added to BCG in female rats with BBN-induced bladder cancer [71]. The mechanism of action seems to be related to modulation of key immunologic factors, including integrin- $\alpha 5 \beta 1, \mathrm{TNF} \alpha$, and interleukins, specifically IL-6, which are up-regulated by ASC-J9 and are thought to enhance the efficacy of BCG on bladder cancer cells [71].

Tamoxifen is an antiestrogen that exerts its effect, in part, by competitively blocking estradiol from binding to the ER. An important characteristic of tamoxifen is that its direct effect on ER action is different in various tissues, allowing it to selectively inhibit or stimulate estrogen-regulated functions in various tissues or organs. For this reason it is also classified as a selective estrogen receptor modulator (SERM). In an early preclinical study, tamoxifen was employed as a chemosensitizing agent that increased the response of bladder cancer cell lines to the cytotoxic agents, methotrexate, vinblastine, doxorubicin and cisplatin in a concentration dependent manner. The basis for this effect was not established, but appeared to be through a mechanism other than modulation of multi-drug resistance gene (MDR-1) as its expression was not affected [72]. This early study did not discuss tamoxifen's antiestrogen effect, but indicated that tamoxifen had a direct cytotoxic effect on bladder cancer cells, leading to the conclusion that intravesical application of this drug should be further explored [73].

Thereafter, Sonpavde and colleagues demonstrated that tamoxifen and raloxifene, both ER antagonists of the SERM class, were able to suppress growth of 5637 transitional cell carcinoma xenografts in nude mice. The average tumor volumes decreased in all studies utilizing the SERMs and 17 out of 30 treated mice 
had no detectable tumor [63]. When assessed in a chemoprevention setting with the BBN-induced bladder cancer model, tamoxifen was able to reduce tumor incidence from $76 \%$ in the control group (BBN alone) to $10-14 \%$, depending upon whether tamoxifen treatment was continued after concurrent tamoxifen and carcinogen treatment [74].

\section{Clinical $A R$ and ER studies}

In a large Japanese multi-centre retrospective cohort study of patients with prostate cancer, investigators assessed the impact of androgen deprivation therapy (ADT) in those who also developed primary bladder cancer. They identified 239 men out of 20,328 subjects diagnosed with prostate cancer between 1991 and 2013. Patients who received ADT for their prostate cancer had a significantly lower recurrence rate $(40 \%$ versus $76 \%, p<0.001)$ for bladder cancer, and also fewer recurrence episodes (5-year cumulative recurrence: 0.44 versus $1.54, p<0.001$ ), when compared to patients who did not receive ADT [75], suggesting a possible therapeutical role for ADT in this disease. Two reports discussed the potential therapeutic role of tamoxifen in advanced bladder cancer disease. One early case report suggested that the regression of metastatic urothelial carcinoma disease could have occurred because of the initiation of tamoxifen indicated for gynecomastia [76]. In another study assessing the potential chemosensitizing effect of tamoxifen, a cohort of 30 patients with bladder cancer ( 9 with muscle-invasive disease, 21 with unresectable or metastatic disease), was treated with high-dose tamoxifen in addition to systemic chemotherapy including cisplatin, methotrexate, and vinblastine (CMV). The lack of control group preclude major conclusions, but the overall response rate of 58\% (1 complete and 14 partial responses) was comparable to historical conventional cisplatin-based combinations [77].

\section{Limitations and clinical implications}

As evidenced in this review, there are very few clinical studies targeting AR and ER in bladder cancer despite the strong and growing body of preclinical data supporting their association in both carcinogenesis and tumor progression via various proposed mechanisms. An acknowledged limitation of the preclinical data is the few number of cell lines that are utilized in the in vitro experiments, and how these findings are correlated and reproduced in human tissue. Similarly, the relevance of bladder cancer mouse models in humans may not yet be completely known.

From the investigational and mechanistic stand point, this work has been instrumental to increase our understanding of the potential roles that these nuclear steroid receptors have in the development and progression of bladder cancer, but more translational and clinical work is required to turn these laboratorial discoveries and observations into viable clinical management tools for patients with this disease. For instance, clinical trials testing the hypothesis of adding ADT or SERMs to current management strategies to different stages of the disease are needed. There are only two clinical trials currently registered in the ClinicalTrials.gov addressing this topic. One is investigating an antiandrogen drug (NCT02605863), and the other is studying a SERM (NCT02197897), both in NMIBC. Targeting both androgen and estrogen receptors and their related signaling pathways has the potential to improve current prevention and treatment strategies in bladder cancer, impacting significantly these patients' oncological outcomes.

\section{CONFLICTS OF INTEREST}

There are no conflicts of interest to report.

\section{REFERENCES}

[1] Torre LA, Bray F, Siegel RL, Ferlay J, Lortet-Tieulent J, Jemal A. Global cancer statistics, 2012. CA Cancer J Clin 2015;65(2):87-108.

[2] Siegel RL, Miller KD, Jemal A. Cancer statistics, 2016. CA Cancer J Clin 2016;66(1):7-30.

[3] Burger M, Catto JW, Dalbagni G, Grossman HB, Herr H, Karakiewicz P, Kassouf W, Kiemeney LA, La Vecchia C, Shariat S, Lotan Y. Epidemiology and risk factors of urothelial bladder cancer. Eur Urol 2013;63(2):234-41.

[4] Babjuk M, Burger M, Zigeuner R, Shariat SF, van Rhijn BW, Comperat E, Sylvester RJ, Kaasinen E, Bohle A, Palou Redorta J, Roupret M. EAU guidelines on non-muscleinvasive urothelial carcinoma of the bladder: Update 2013. Eur Urol 2013;64(4):639-53.

[5] Witjes JA, Comperat E, Cowan NC, De Santis M, Gakis G, Lebret T, Ribal MJ, Van der Heijden AG, Sherif A. EAU guidelines on muscle-invasive and metastatic bladder cancer: Summary of the 2013 guidelines. Eur Urol 2014;65(4):778-92.

[6] Malmstrom PU, Sylvester RJ, Crawford DE, Friedrich M, Krege S, Rintala E, Solsona E, Di Stasi SM, Witjes JA. An individual patient data meta-analysis of the long-term outcome of randomised studies comparing intravesical mitomycin $\mathrm{C}$ versus bacillus CalmetteGuerin for non-muscle-invasive bladder cancer. Eur Urol 2009;56(2):247-56.

[7] Brausi M, Oddens J, Sylvester R, Bono A, van de Beek C, van Andel G, Gontero P, Turkeri L, Marreaud S, Collette S, 
Oosterlinck W. Side effects of Bacillus Calmette-Guerin $(\mathrm{BCG})$ in the treatment of intermediate- and high-risk Ta, T1 papillary carcinoma of the bladder: Results of the EORTC genito-urinary cancers group randomised phase 3 study comparing one-third dose with full dose and 1 year with 3 years of maintenance BCG. Eur Urol 2014;65(1): 69-76.

[8] Jakse G, Hall R, Bono A, Holtl W, Carpentier P, Spaander JP, van der Meijden AP, Sylvester R. Intravesical BCG in patients with carcinoma in situ of the urinary bladder: Longterm results of EORTC GU Group phase II protocol 30861. Eur Urol 2001;40(2):144-50.

[9] Bolenz C, Lotan Y, Ashfaq R, Shariat SF. Estrogen and progesterone hormonal receptor expression in urothelial carcinoma of the bladder. Eur Urol 2009;56(6):1093-5.

[10] Boorjian S, Ugras S, Mongan NP, Gudas LJ, You X, Tickoo SK, Scherr DS. Androgen receptor expression is inversely correlated with pathologic tumor stage in bladder cancer. Urology 2004;64(2):383-8

[11] Mir C, Shariat SF, van der Kwast TH, Ashfaq R, Lotan Y, Evans A, Skeldon S, Hanna S, Vajpeyi R, Kuk C, Alkhateeb S, Morote J, van Rhijn BW, Bostrom P, Yao J, Miyamoto H, Jewett M, Fleshner N, Messing E, Zlotta AR. Loss of androgen receptor expression is not associated with pathological stage, grade, gender or outcome in bladder cancer: A large multi-institutional study. BJU Int 2011;108(1):24-30.

[12] Waliszewski P, Waliszewska MK, Hemstreet GP 3rd, Hurst RE. Expression of sex steroid receptor genes and comodulation with retinoid signaling in normal human uroepithelial cells and bladder cancer cell lines. Urol Oncol 1997;3(56):141-7.

[13] Castelao JE, Yuan JM, Skipper PL, Tannenbaum SR, GagoDominguez M, Crowder JS, Ross RK, Yu MC. Genderand smoking-related bladder cancer risk. J Natl Cancer Inst 2001;93(7):538-45.

[14] Hartge P, Harvey EB, Linehan WM, Silverman DT, Sullivan JW, Hoover RN, Fraumeni JF Jr. Unexplained excess risk of bladder cancer in men. J Natl Cancer Inst 1990;82(20): 1636-40.

[15] Scelo G, Brennan P. The epidemiology of bladder and kidney cancer. Nat Clin Pract Urol 2007;4(4):205-17.

[16] Mungan NA, Aben KK, Schoenberg MP, Visser O, Coebergh JW, Witjes JA, Kiemeney LA. Gender differences in stage-adjusted bladder cancer survival. Urology 2000;55(6):876-80.

[17] Najari BB, Rink M, Li PS, Karakiewicz PI, Scherr DS, Shabsigh R, Meryn S, Schlegel PN, Shariat SF. Sex disparities in cancer mortality: The risks of being a man in the United States. J Urol 2013;189(4):1470-4.

[18] Vaidya A, Soloway MS, Hawke C, Tiguert R, Civantos F. De novo muscle invasive bladder cancer: Is there a change in trend? J Urol 2001;165(1):47-50; discussion

[19] Otto W, May M, Fritsche HM, Dragun D, Aziz A, Gierth M, Trojan L, Herrmann E, Moritz R, Ellinger J, Tilki D, Buchner A, Hofner T, Brookman-May S, Nuhn P, Gilfrich C, Roigas J, Zacharias M, Denzinger S, Hohenfellner M, Haferkamp A, Muller SC, Kocot A, Riedmiller H, Wieland WF, Stief CG, Bastian PJ, Burger M. Analysis of sex differences in cancer-specific survival and perioperative mortality following radical cystectomy: Results of a large German multicenter study of nearly 2500 patients with urothelial carcinoma of the bladder. Gend Med 2012;9(6):481-9.

[20] Sammon JD, Morgan M, Djahangirian O, Trinh QD, Sun M, Ghani KR, Jeong W, Jhaveri J, Ehlert M, Schmitges J, Bianchi M, Shariat SF, Perrotte P, Rogers CG, Peabody
JO, Menon M, Karakiewicz PI. Marital status: A genderindependent risk factor for poorer survival after radical cystectomy. BJU Int 2012;110(9):1301-9.

[21] Shariat SF, Sfakianos JP, Droller MJ, Karakiewicz PI, Meryn $\mathrm{S}$, Bochner BH. The effect of age and gender on bladder cancer: A critical review of the literature. BJU Int 2010; 105(3):300-8

[22] Fernandez-Gomez J, Madero R, Solsona E, Unda M, Martinez-Pineiro L, Gonzalez M, Portillo J, Ojea A, Pertusa C, Rodriguez-Molina J, Camacho JE, Rabadan M, Astobieta A, Montesinos M, Isorna S, Muntanola P, Gimeno A, Blas M, Martinez-Pineiro JA. Predicting nonmuscle invasive bladder cancer recurrence and progression in patients treated with bacillus Calmette-Guerin: The CUETO scoring model. J Urol 2009;182(5):2195-203.

[23] Fernandez-Gomez J, Solsona E, Unda M, Martinez-Pineiro L, Gonzalez M, Hernandez R, Madero R, Ojea A, Pertusa C, Rodriguez-Molina J, Camacho JE, Isorna S, Rabadan M, Astobieta A, Montesinos M, Muntanola P, Gimeno A, Blas M, Martinez-Pineiro JA. Prognostic factors in patients with non-muscle-invasive bladder cancer treated with bacillus Calmette-Guerin: Multivariate analysis of data from four randomized CUETO trials. Eur Urol 2008;53(5): 992-1001.

[24] Kluth LA, Fajkovic H, Xylinas E, Crivelli JJ, Passoni N, Roupret M, Becker A, Comploj E, Pycha A, Holmang S, Gupta A, Lotan Y, Karakiewicz PI, Gontero P, Chun FK, Fisch M, Scherr DS, Shariat SF. Female gender is associated with higher risk of disease recurrence in patients with primary T1 high-grade urothelial carcinoma of the bladder. World J Urol 2013;31(5):1029-36.

[25] Boorjian SA, Zhu F, Herr HW. The effect of gender on response to bacillus Calmette-Guerin therapy for patients with non-muscle-invasive urothelial carcinoma of the bladder. BJU Int 2010;106(3):357-61.

[26] Nam JK, Park SW, Lee SD, Chung MK. Prognostic value of sex-hormone receptor expression in non-muscle-invasive bladder cancer. Yonsei Med J 2014;55(5):1214-21.

[27] Williams EM, Higgins JP, Sangoi AR, McKenney JK, Troxell ML. Androgen receptor immunohistochemistry in genitourinary neoplasms. Int Urol Nephrol 2015;47(1):81-5.

[28] Zhuang YH, Blauer M, Tammela T, Tuohimaa P. Immunodetection of androgen receptor in human urinary bladder cancer. Histopathology 1997;30(6):556-62.

[29] Downes MR, Torlakovic EE, Aldaoud N, Zlotta AR, Evans AJ, van der Kwast TH. Diagnostic utility of androgen receptor expression in discriminating poorly differentiated urothelial and prostate carcinoma. J Clin Pathol 2013;66(9):779-86.

[30] Mohanty SK, Smith SC, Chang E, Luthringer DJ, Gown AM, Aron M, Amin MB. Evaluation of contemporary prostate and urothelial lineage biomarkers in a consecutive cohort of poorly differentiated bladder neck carcinomas. Am J Clin Pathol 2014;142(2):173-83.

[31] Mashhadi R, Pourmand G, Kosari F, Mehrsai A, Salem S, Pourmand MR, Alatab S, Khonsari M, Heydari F, Beladi L, Alizadeh F. Role of steroid hormone receptors in formation and progression of bladder carcinoma: A case-control study. Urol J 2014;11(6):1968-73.

[32] Tuygun C, Kankaya D, Imamoglu A, Sertcelik A, Zengin K, Oktay M, Sertcelik N. Sex-specific hormone receptors in urothelial carcinomas of the human urinary bladder: A comparative analysis of clinicopathological features and survival outcomes according to receptor expression. Urol Oncol 2011;29(1):43-51. 
[33] Laor E, Schiffman ZJ, Braunstein JD, Reid RE, Tolia BM, Koss LG, Freed SZ. Androgen receptors in bladder tumors. Urology 1985;25(2):161-3.

[34] Miyamoto H, Yao JL, Chaux A, Zheng Y, Hsu I, Izumi K, Chang C, Messing EM, Netto GJ, Yeh S. Expression of androgen and oestrogen receptors and its prognostic significance in urothelial neoplasm of the urinary bladder. BJU Int 2012;109(11):1716-26.

[35] Boorjian SA, Heemers HV, Frank I, Farmer SA, Schmidt LJ, Sebo TJ, Tindall DJ. Expression and significance of androgen receptor coactivators in urothelial carcinoma of the bladder. Endocr Relat Cancer 2009;16(1):123-37.

[36] Kauffman EC, Robinson BD, Downes MJ, Powell LG, Lee MM, Scherr DS, Gudas LJ, Mongan NP. Role of androgen receptor and associated lysine-demethylase coregulators, LSD1 and JMJD2A, in localized and advanced human bladder cancer. Mol Carcinog 2011;50(12):931-44.

[37] Comprehensive molecular characterization of urothelial bladder carcinoma. Nature 2014;507(7492):315-22.

[38] Choi W, Porten S, Kim S, Willis D, Plimack ER, HoffmanCensits J, Roth B, Cheng T, Tran M, Lee IL, Melquist J, Bondaruk J, Majewski T, Zhang S, Pretzsch S, Baggerly K, Siefker-Radtke A, Czerniak B, Dinney CP, McConkey DJ. Identification of distinct basal and luminal subtypes of muscle-invasive bladder cancer with different sensitivities to frontline chemotherapy. Cancer Cell 2014;25(2):152-65.

[39] Damrauer JS, Hoadley KA, Chism DD, Fan C, Tiganelli CJ, Wobker SE, Yeh JJ, Milowsky MI, Iyer G, Parker JS, Kim WY. Intrinsic subtypes of high-grade bladder cancer reflect the hallmarks of breast cancer biology. Proc Natl Acad Sci U S A 2014;111(8):3110-5.

[40] Heemers HV, Tindall DJ. Androgen receptor (AR) coregulators: A diversity of functions converging on and regulating the AR transcriptional complex. Endocr Rev 2007;28(7):778-808.

[41] Luo JH, Xie D, Liu MZ, Chen W, Liu YD, Wu GQ, Kung HF, Zeng YX, Guan XY. Protein expression and amplification of AIB1 in human urothelial carcinoma of the bladder and overexpression of AIB 1 is a new independent prognostic marker of patient survival. Int J Cancer 2008;122(11): 2554-61.

[42] Tong ZT, Wei JH, Zhang JX, Liang CZ, Liao B, Lu J, Fan S, Chen ZH, Zhang F, Ma HH, Qian WC, Kong LL, Fang Y, Chen W, Xie D, Luo JH. AIB1 predicts bladder cancer outcome and promotes bladder cancer cell proliferation through AKT and E2F1. Br J Cancer 2013;108(7):1470-9.

[43] Kihara K, Fukui I, Higashi Y, Oshima H. Inhibitory effect of testosterone on gap junctional intercellular communication of human transitional cell carcinoma cell lines. Cancer Res 1990;50(9):2848-52.

[44] Wu JT, Han BM, Yu SQ, Wang HP, Xia SJ. Androgen receptor is a potential therapeutic target for bladder cancer. Urology 2010;75(4):820-7.

[45] Hsu JW, Hsu I, Xu D, Miyamoto H, Liang L, Wu XR, Shyr $\mathrm{CR}$, Chang C. Decreased tumorigenesis and mortality from bladder cancer in mice lacking urothelial androgen receptor. Am J Pathol 2013;182(5):1811-20.

[46] Li Y, Zheng Y, Izumi K, Ishiguro H, Ye B, Li F, Miyamoto H. Androgen activates beta-catenin signaling in bladder cancer cells. Endocr Relat Cancer 2013;20(3):293-304.

[47] Zheng Y, Izumi K, Yao JL, Miyamoto H. Dihydrotestosterone upregulates the expression of epidermal growth factor receptor and ERBB2 in androgen receptor-positive bladder cancer cells. Endocr Relat Cancer 2011;18(4): 451-64.
[48] Miyamoto H, Yang Z, Chen YT, Ishiguro H, Uemura H, Kubota Y, Nagashima Y, Chang YJ, Hu YC, Tsai MY, Yeh S, Messing EM, Chang C. Promotion of bladder cancer development and progression by androgen receptor signals. J Natl Cancer Inst 2007;99(7):558-68.

[49] Terada S, Suzuki N, Uchide K, Akasofu K, Nishida E. Effect of testosterone on the development of bladder tumors and calculi in female rats. Gynecol Obstet Invest 1992;34(2): 105-10

[50] Okajima E, Hiramatsu T, Iriya K, Ijuin M, Matsushima S. Effects of sex hormones on development of urinary bladder tumours in rats induced by N-butyl-N-(4-hydroxybutyl) nitrosamine. Urol Res 1975;3(2):73-9.

[51] Ciotti M, Lakshmi VM, Basu N, Davis BB, Owens IS, Zenser TV. Glucuronidation of benzidine and its metabolites by cDNA-expressed human UDP-glucuronosyl transferases and $\mathrm{pH}$ stability of glucuronides. Carcinogenesis 1999;20(10):1963-9.

[52] Izumi K, Zheng Y, Hsu JW, Chang C, Miyamoto H. Androgen receptor signals regulate UDP-glucuronosyl transferases in the urinary bladder: A potential mechanism of androgen-induced bladder carcinogenesis. Mol Carcinog 2013;52(2):94-102.

[53] Kauffman EC, Robinson BD, Downes M, Marcinkiewicz K, Vourganti S, Scherr DS, Gudas LJ, Mongan NP. Estrogen receptor-beta expression and pharmacological targeting in bladder cancer. Oncol Rep 2013;30(1):131-8.

[54] Shen SS, Smith CL, Hsieh JT, Yu J, Kim IY, Jian W, Sonpavde G, Ayala GE, Younes M, Lerner SP. Expression of estrogen receptors-alpha and -beta in bladder cancer cell lines and human bladder tumor tissue. Cancer 2006; 106(12):2610-6.

[55] Teng J, Wang ZY, Jarrard DF, Bjorling DE. Roles of estrogen receptor alpha and beta in modulating urothelial cell proliferation. Endocr Relat Cancer 2008;15(1):351-64.

[56] Croft PR, Lathrop SL, Feddersen RM, Joste NE. Estrogen receptor expression in papillary urothelial carcinoma of the bladder and ovarian transitional cell carcinoma. Arch Pathol Lab Med 2005;129(2):194-9.

[57] Han B, Cui D, Jing Y, Hong Y, Xia S. Estrogen receptor beta (ERbeta) is a novel prognostic marker of recurrence survival in non-muscle-invasive bladder cancer potentially by inhibiting cadherin switch. World J Urol 2012;30(6): 861-7.

[58] Kaufmann O, Baume H, Dietel M. Detection of oestrogen receptors in non-invasive and invasive transitional cell carcinomas of the urinary bladder using both conventional immunohistochemistry and the tyramide staining amplification (TSA) technique. J Pathol 1998;186(2): 165-8.

[59] Kontos S, Kominea A, Melachrinou M, Balampani E, Sotiropoulou-Bonikou G. Inverse expression of estrogen receptor-beta and nuclear factor-kappaB in urinary bladder carcinogenesis. Int J Urol 2010;17(9):801-9.

[60] Tan W, Boorjian S, Advani P, Farmer S, Lohse C, Cheville J, Kwon E, Leibovich B. The estrogen pathway: Estrogen receptor-alpha, progesterone receptor, and estrogen receptor-beta expression in radical cystectomy urothelial cell carcinoma specimens. Clin Genitourin Cancer 2015;13(5):476-84

[61] Wei S, Said-Al-Naief N, Hameed O. Estrogen and progesterone receptor expression is not always specific for mammary and gynecologic carcinomas: A tissue microarray and pooled literature review study. Appl Immunohistochem Mol Morphol 2009;17(5):393-402. 
[62] Hoffman KL, Lerner SP, Smith CL. Raloxifene inhibits growth of RT4 urothelial carcinoma cells via estrogen receptor-dependent induction of apoptosis and inhibition of proliferation. Horm Cancer 2013;4(1):24-35.

[63] Sonpavde G, Okuno N, Weiss H, Yu J, Shen SS, Younes M, Jian W, Lerner SP, Smith CL. Efficacy of selective estrogen receptor modulators in nude mice bearing human transitional cell carcinoma. Urology 2007;69(6):1221-6.

[64] Izumi K, Li Y, Ishiguro H, Zheng Y, Yao JL, Netto GJ, Miyamoto $\mathrm{H}$. Expression of UDP-glucuronosyltransferase $1 \mathrm{~A}$ in bladder cancer: Association with prognosis and regulation by estrogen. Mol Carcinog 2014;53(4):314-24.

[65] Hsu I, Chuang KL, Slavin S, Da J, Lim WX, Pang ST, O'Brien JH, Yeh S. Suppression of ERbeta signaling via ERbeta knockout or antagonist protects against bladder cancer development. Carcinogenesis 2014;35(3):651-61.

[66] Yeh CR, Hsu I, Song W, Chang H, Miyamoto H, Xiao GQ, $\mathrm{Li}$ L, Yeh S. Fibroblast ERalpha promotes bladder cancer invasion via increasing the CCL1 and IL-6 signals in the tumor microenvironment. Am J Cancer Res 2015;5(3):1146-57.

[67] Hsu I, Yeh CR, Slavin S, Miyamoto H, Netto GJ, Tsai YC, Muyan M, Wu XR, Messing EM, Guancial EA, Yeh $\mathrm{S}$. Estrogen receptor alpha prevents bladder cancer via INPP4B inhibited akt pathway in vitro and in vivo. Oncotarget 2014;5(17):7917-35.

[68] Johnson AM, O'Connell MJ, Miyamoto H, Huang J, Yao JL, Messing EM, Reeder JE. Androgenic dependence of exophytic tumor growth in a transgenic mouse model of bladder cancer: A role for thrombospondin-1. BMC Urol 2008;8:7.

[69] Zhang ZT, Pak J, Shapiro E, Sun TT, Wu XR. Urotheliumspecific expression of an oncogene in transgenic mice induced the formation of carcinoma in situ and invasive transitional cell carcinoma. Cancer Res 1999;59(14):3512-7.

[70] Garcia PV, Apolinario LM, Bockelmann PK, da Silva Nunes I, Duran N, Favaro WJ. Alterations in ubiquitin ligase Siah-2 and its corepressor N-CoR after P-MAPA immunotherapy and anti-androgen therapy: New therapeutic opportunities for non-muscle invasive bladder cancer. Int J Clin Exp Pathol 2015;8(5):4427-43.

[71] Shang Z, Li Y, Zhang M, Tian J, Han R, Shyr CR, Messing E, Yeh S, Niu Y, Chang C. Antiandrogen therapy with hydroxyflutamide or androgen receptor degradation enhancer ASC-J9 enhances BCG efficacy to better suppress bladder cancer progression. Mol Cancer Ther 2015;14(11):2586-94.

[72] Pu YS, Hsieh TS, Tsai TC, Cheng AL, Hsieh CY, Su IJ, Lai MK. Tamoxifen enhances the chemosensitivity of bladder carcinoma cells. J Urol 1995;154(2 Pt 1):601-5.

[73] Pu YS, Hsieh TS, Cheng AL, Tseng NF, Su IJ, Hsieh CY, Lai MK, Tsai TC. Combined cytotoxic effects of tamoxifen and chemotherapeutic agents on bladder cancer cells: A potential use in intravesical chemotherapy. Br J Urol 1996;77(1):76-85.

[74] George SK, Tovar-Sepulveda V, Shen SS, Jian W, Zhang Y, Hilsenbeck SG, Lerner SP, Smith CL. Chemoprevention of $\mathrm{BBN}$-induced bladder carcinogenesis by the selective estrogen receptor modulator tamoxifen. Transl Oncol 2013;6(3):244-55.

[75] Izumi K, Taguri M, Miyamoto H, Hara Y, Kishida T, Chiba K, Murai T, Hirai K, Suzuki K, Fujinami K, Ueki T, Udagawa K, Kitami K, Moriyama M, Miyoshi Y, Tsuchiya F, Ikeda I, Kobayashi K, Sato M, Morita S, Noguchi K, Uemura H. Androgen deprivation therapy prevents bladder cancer recurrence. Oncotarget 2014;5(24):12665-74.

[76] Dellagrammaticas D, Bryden AA, Collins GN. Regression of metastatic transitional cell carcinoma in response to tamoxifen. J Urol 2001;165(5):1631.

[77] Hsu CH, Chen J, Wu CY, Cheng AL, Pu YS. Combination chemotherapy of cisplatin, methotrexate, vinblastine, and high-dose tamoxifen for transitional cell carcinoma. Anticancer Res 2001;21(1B):711-5. 